\title{
Household preferences and willingness to pay for health insurance in Kampala City: a discrete choice experiment
}

\author{
Edward Kalyango ${ }^{1^{*}} \mathbb{0}$, Rornald Muhumuza Kananura ${ }^{2}$ and Elizabeth Ekirapa Kiracho ${ }^{1}$
}

\begin{abstract}
Introduction: Uganda is in discussions to introduce a national health insurance scheme. However, there is a paucity of information on household preferences and willingness to pay for health insurance attributes that may guide the design of an acceptable health insurance scheme. Our study sought to assess household preferences and willingness to pay for health insurance in Kampala city using a discrete choice experiment.
\end{abstract}

Methods: This study was conducted from 16th February 2020 to 10th April 2020 on 240 households in the Kawempe division of Kampala city stratified into slum and non-slum communities in order to get a representative sample of the area. We purposively selected the communities that represented slum and non-slum communities and thereafter applied systematic sampling in the selection of the households that participated in the study from each of the communities. Four household and policy-relevant attributes were used in the experimental design of the study. Each respondent attended to 9 binary choice sets of health insurance plans that included one fixed choice set. Data were analyzed using mixed logit models.

Results: Households in both the non-slum and slum communities had a high preference for health insurance plans that included both private and public health care providers as compared to plans that included public health care providers only (non-slum coefficient $\beta=0.81, P<0.05$; slum $\beta=0.87, p<0.05$ ) and; health insurance plans that covered extended family members as compared to plans that had limitations on the number of family members allowed (non-slum $\beta=0.44, P<0.05$; slum $\beta=0.36, p<0.05$ ). Households in non-slum communities, in particular, had a high preference for health insurance plans that covered chronic illnesses and major surgeries to other plans ( 0.97 $\beta, P<0.05)$. Our findings suggest that location of the household influences willingness to pay with households from non-slum communities willing to pay more for the preferred attributes.

Conclusion: Potential health insurance schemes should consider including both private and public health care providers and allow more household members to be enrolled in both slum and non-slum communities. However, the inclusion of more $\mathrm{HH}$ members should be weighed against the possible depletion of resources and other attributes. Potential health insurance schemes should also prioritize coverage for chronic illnesses and major surgeries in nonslum communities, in particular, to make the scheme attractive and acceptable for these communities.

Keywords: Health insurance, Discrete choice experiment, Preferences, Willingness to pay, Kampala, Uganda

*Correspondence: kalyango.edward.edward@gmail.com 1 Department of Health Policy and Planning, School of Public Health, College of Health Sciences, Makerere University, Kampala, Uganda Full list of author information is available at the end of the article

\section{Introduction}

According to the sustainable development goal 3, target 8 , member countries of the United Nations agreed to achieve universal health coverage (UHC) including: 
financial risk protection; access to quality essential health care services and; access to safe, effective, quality, and affordable essential medicines and vaccines for all by 2030 [1]. Low and middle-income countries face challenges in achieving UHC due to limited public resources, inefficient resource allocation, reliance on out-of-pocket (OOP) expenditures, and large population sizes [2]. For example, the current health expenditure as a percentage of gross domestic product (GDP) for sub-Saharan Africa is estimated at $5.2 \%$, which is almost $50 \%$ lower than the global average (9.9\%). In Uganda, the health expenditure as a share of the national GDP is almost $70 \%$ and $50 \%$ lower than the estimates for North America (16.6\%) and the European Union (9.9\%), respectively [3]. The Uganda government's health expenditure as a share of its GDP and its health expenditure per capita are estimated at $0.97 \%$ and USD (United States dollars) 38.4, respectively. These estimates are less than the Working Group on Health Financing's recommended health sectors' share of GDP and health expenditure per capita that are expected to be at least $5 \%$ and USD 86 , respectively [3-5].

The lower health sector's share of the national GDP in Uganda indicates inadequacies in health financing, which may explain why $40 \%$ of the country's health expenditure is OOP expenditure. The OOP expenditures in Uganda are two times higher than the World Health Organization (WHO)'s recommendation of $20 \%$ of the total health expenditure in a country $[2,4,5]$. This calls for more financial risk protection for the HHs in Uganda to protect them against OOP expenditures and their consequences (catastrophic health expenditure and impoverishment) [2]. Taxes and health insurance are the means recommended by the WHO to raise funds for the health sector in low and middle-income countries in order to achieve UHC (including financial risk protection) $[2,6]$. Taxes and health insurance have shown good results in other African countries such as Ghana and Rwanda providing increased financial risk protection and increased service utilization $[7,8]$.

Uganda is in discussions to introduce a National Health Insurance Scheme (NHIS) in order to reduce OOP expenditures and raise adequate funds for its health sector [9]. The existing health insurance schemes in the country are mainly provided by the private sector and contribute less than $3 \%$ of the total health financing in the country and are often accessed by those in formal employment [5]. There has been some success with community health insurance schemes that usually target rural communities--indicating the communities' interest in saving for health. However, these community health insurance schemes are usually based on subscription membership fees that are often low and cannot cover long hospitalizations and severe illnesses $[10,11]$.
A successful NHIS requires a scheme that has been well thought out and that reflects HHs' preferences. In this study, we assessed HHs' preferences and WTP for health insurance. Specifically, we focused on: (1) identifying differences between the $\mathrm{HHs}$ in slum and non-slum communities that may influence their choice of health insurance plan; (2) determining preferences for the attributes of health insurance by $\mathrm{HHs}$ and; (3) estimating WTP for health insurance by HHs. We applied a discrete choice experiment (DCE) approach that is different from the contingent valuation methods used in the prior studies conducted in Uganda. Contingent valuation methods can assess the total value of a commodity including the passive-use value but cannot determine the importance and the value $\mathrm{HHs}$ attach to the health insurance attributes [12-15]. Understanding the importance and value $\mathrm{HHs}$ attach to the different attributes of health insurance is critical in informing the design of an acceptable health insurance scheme [16-18].

\section{Methods \\ Study design and study area}

This was a DCE that was conducted from 16th February 2020 to 10th April 2020 in two parishes of the Kawempe division of Kampala capital city of Uganda. The Katanga slum represented the slum communities, while the Kyebando parish represented the non-slum communities in Kampala [19]. We chose this study setting because Kampala is the most populous urban center in the country with over 1.5 million people ( $31 \%$ of the urban population in the country); has more public and private health care facilities including several specialized public health care facilities compared with any other district in the country and; has a representation of the many tribes from all over the country [20-22]. We decided to stratify the study area into slum and non-slum communities in order to get a representative sample of the City, which has over $60 \%$ of the population living in slums [23]. Finally, we chose to conduct the study in the Kawempe division because of budget constraints and because we assumed that the population in the City is mainly divided into slum and non-slum dwellers. Figure 1 describes the study design.

\section{Development of the DCE \\ Choosing attributes and levels}

In line with recommendations, a two-stage approach was used to generate attributes and levels [24-28]. First, conceptual attributes were identified from the literature and policy documents. We identified over 20 attributes from the literature review. The candidate attributes from the literature review that were relevant to Uganda included: premiums; the unit of enrollment; the type of health care providers; the service benefits package 


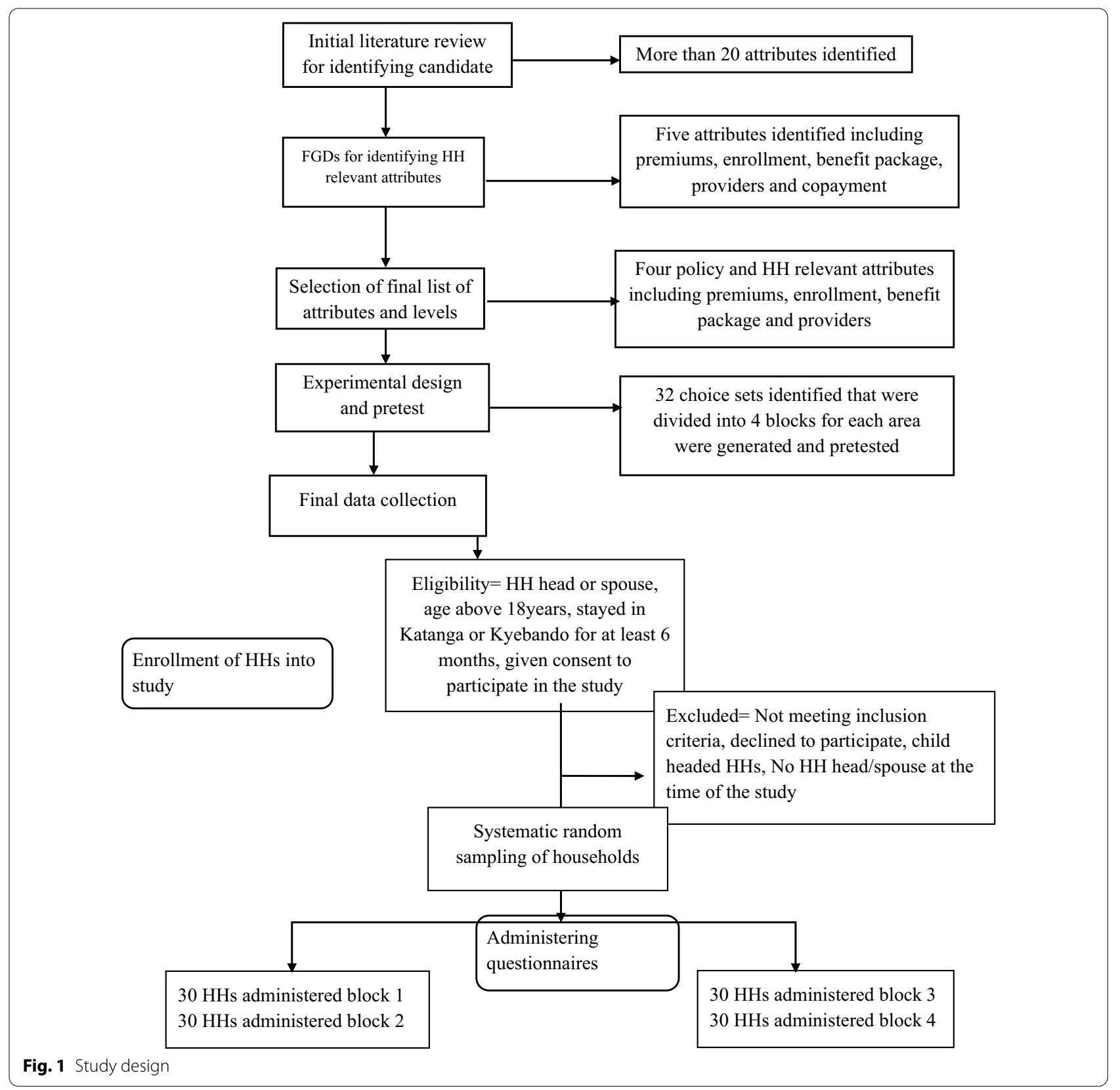

and; the copayment levels $[9,16,29-35]$. These candidate attributes were used to guide the design of the FGD guide (Additional file 1). Second, four focused group discussions (FGDs) were conducted in each area to ensure that the identified attributes from the literature were relevant to the HHs and to identify new ones. We probed participants on factors that would influence them to join a health insurance plan. We asked them specific questions about the potentially relevant attributes that we had earlier identified from the literature review. Participants were also asked to rank the attributes in order of importance. The FGDs were carried out by the first author with assistance from one research assistant in Luganda and English. We audio-recorded and later transcribed the data verbatim. We then translated the transcripts into English. We analyzed the data using both deductive and inductive thematic approaches. The main themes from the FGDs were related to premiums, providers of health services, unit of enrollment, and service benefits packages.

Premiums: The Ministry of Health $(\mathrm{MoH})$ for Uganda proposed that self-employed individuals contribute UGX 
100,000 (USD 26.7) (based on currency conversion rates from the OANDA website) [36] annually to the scheme, while salaried employees contribute $4 \%$ of their salary to the scheme [9]. The $4 \%$ is equivalent to UGX 68,000 (USD 18.1) to UGX 450,000 per year (USD 120) (based on average income ranges from the Uganda national household survey 2016/2017) [36, 37]. The employers would then be required to provide an additional $1 \%$ of the employee's salary (in addition to the $4 \%$ contribution by the employee) $[5,37]$. From the FGDs, participants from the slum area suggested premiums that ranged from UGX 20,000 (USD 5.3) per year to UGX 100,000 (USD 26.7) per year, while participants from the non-slum area suggested premiums that ranged from UGX 100,000 (USD 26.7) per year to UGX 300,000 (USD 80.0) per year. Therefore, for this attribute, we included levels that ranged from UGX 20,000 per year to UGX 100,000 per year for the slum community and UGX 100,000 per year to UGX 300,000 per year for the non-slum community.

Providers: From the literature, this attribute was mainly categorized depending on the way the health systems from the countries where the studies originated were organized. In some countries like Iran and Thailand, there were no faith-based health care providers while in Africa, they were common $[29,30,32,33,38]$. The majority of participants in the FGDs from both the slum and non-slum communities wanted to receive health services from both public and private health care providers, while a minority wanted to receive health services from private health care providers only. Therefore, for this attribute, we included the following levels: private health care providers only; both private and public health care providers and; public health care providers only. The private health care providers in our study included both private and faith-based health care providers.

Unit of enrollment: From the literature review, this attribute was categorized based on the type and number of family members the insurance plan is responsible for. For example, it was categorized by some researchers as self only, self plus spouse, self plus spouse plus children, and self plus extended family [29,33,34]. For the case of Uganda, the $\mathrm{MoH}$ proposed that the beneficiaries include the individual who pays for the health insurance plan, their spouse, and one of their children below the age of 18 years [9]. From the FGDs, the majority of participants were not interested in any health insurance plan that did not cover extended family members. The Majority of participants concerned with the depletion of resources suggested a restriction on the number of children enrolled to three per $\mathrm{HH}$. Therefore, for this attribute, we considered the following levels: restricted enrollment (parents and their three children); unrestricted enrollment (parents without limitations on the number of children enrolled) and; extended family enrollment (parents, their children, and grandparents).

Service benefits package: From the literature review, this attribute was categorized as follows: basic, medium, and comprehensive benefits packages $[29,30]$ and; inpatient department services, outpatient department services, and drugs and tests [33]. From the FGDs, the majority of participants from the slum area pointed out that they were disproportionately affected by all diseases and therefore wanted all health conditions to be covered by the health insurance scheme. Others wanted some limitations on the type of health conditions covered by the health insurance scheme to avoid reckless use and depletion of resources. Participants from the non-slum community were equally divided with some wanting all health conditions covered, while others wanted some restrictions on the type of health conditions that health insurance covers. Therefore, in our study, this attribute included the following levels: simple service benefits package; moderate service benefits package and; comprehensive service benefits package. These attribute levels are defined in Table 1.

\section{Development of the DCE questionnaire}

We used experimental design methods to derive choice sets. From the literature, two approaches are commonly used to design choice sets namely: orthogonal methods and D-optimal methods [39]. We used D-optimal methods because they perform better than orthogonal designs and require fewer choice sets and sample sizes compared to orthogonal designs [26]. The generated designs had 32 choice sets that were organized into 4 blocks to reduce the cognitive burden on each respondent. Each $\mathrm{HH}$ head/spouse answered 9 choice sets that included a fixed choice question that was not part of the experimental design and was used to assess the predictive power of the models.

Before the final data collection, we pilot tested the questionnaires on a total of $30 \mathrm{HHs}(15 \mathrm{HHs}$ from each area) and made minor revisions to the questionnaires. The DCE questionnaire collected data on the characteristics of the HHs, the choice sets, and the socio-economic status of the HHs.

Figure 2 shows an example of a choice set. The data collection tools were in English and Luganda (the most commonly spoken languages in the area).

\section{Study population, sample size, study variables, sampling procedure, and data collection}

We targeted HH heads/spouses in the Kawempe division of Kampala city who had stayed for at least 6 months in the area and were at least 18 years of age at the time of conducting this study. We left out child-headed HHs and 
Table 1 Summary of attributes and levels

\begin{tabular}{|c|c|c|c|c|}
\hline Attribute & Description & Regression label & $\begin{array}{l}\text { Non-slum community } \\
\text { Levels }\end{array}$ & $\begin{array}{l}\text { Slum community } \\
\text { Levels }\end{array}$ \\
\hline Premiums $^{\mathrm{a}}$ & $\begin{array}{l}\text { The yearly cost of the health insur- } \\
\text { ance plan }\end{array}$ & Premiums & $\begin{array}{l}\text { 1. UGX 100,000 (USD 26.7) } \\
\text { 2. UGX 200,000 (USD 53.3) } \\
\text { 3. UGX 300,000 (USD 80.0) }\end{array}$ & $\begin{array}{l}\text { 1. UGX 20,000 (USD 5.3) } \\
\text { 2. UGX 50,000 (USD 13.3) } \\
\text { 3. UGX 100,000 (USD 26.7) }\end{array}$ \\
\hline Providers ${ }^{b}$ & $\begin{array}{l}\text { The kind of health providers from } \\
\text { which households will receive } \\
\text { services }\end{array}$ & $\begin{array}{l}\text { 1. Private } \\
\text { 2. Both } \\
\text { 3. Reference level }\end{array}$ & $\begin{array}{l}\text { 1. Private providers only } \\
\text { 2. Public and private providers } \\
\text { 3. Public providers }\end{array}$ & $\begin{array}{l}\text { 1. Private providers only } \\
\text { 2. Public and private providers } \\
\text { 3. Public providers }\end{array}$ \\
\hline Enrollment ${ }^{c}$ & $\begin{array}{l}\text { The type and number of family } \\
\text { members that health insurance is } \\
\text { responsible for }\end{array}$ & $\begin{array}{l}\text { 1. Restrict } \\
\text { 2. Extend } \\
\text { 3. Reference level }\end{array}$ & $\begin{array}{l}\text { 1. Restricted enrollment of children } \\
\text { to } 3 \\
\text { 2. Extended family } \\
\text { 3. Unrestricted enrollment of } \\
\text { children }\end{array}$ & $\begin{array}{l}\text { 1. Restricted enrollment of children } \\
\text { to } 3 \\
\text { 2. Extended family } \\
\text { 3. Unrestricted enrollment of children }\end{array}$ \\
\hline $\begin{array}{l}\text { Health Service } \\
\text { benefits }^{\text {package }}\end{array}$ & $\begin{array}{l}\text { The type of health services covered } \\
\text { by the health insurance plan }\end{array}$ & $\begin{array}{l}\text { 1. Simple } \\
\text { 2. Reference level } \\
\text { 3. Comprehensive }\end{array}$ & $\begin{array}{l}\text { 1. Simple service benefits package } \\
\text { 2. Moderate service benefits pack- } \\
\text { age } \\
\text { 3. Comprehensive service benefits } \\
\text { package }\end{array}$ & $\begin{array}{l}\text { 1. Simple service benefits package } \\
\text { 2. Moderate service benefits package } \\
\text { 3. Comprehensive service benefits } \\
\text { package }\end{array}$ \\
\hline
\end{tabular}

a 1 USD $=3750$ UGX (April 2020 exchange rate)

b Public providers include health facilities that are owned by the government; private providers include health facilities that are owned by private individuals and faith-based organizations

c Restricted enrollment of children includes parents and only three children; unrestricted enrollment of children includes parents with no restrictions on the number of children and; the extended family includes children, their parents, and grandparents

d Simple service benefits package includes primary health care diseases, minor surgeries, ANC, family planning: moderate service benefits package includes chronic illnesses for example asthma, hypertension, and diabetes, major surgeries including caesarian sections and; comprehensive service benefits package includes cancers, advanced kidney diseases, heart surgeries, neurosurgeries, ICU, and special care units

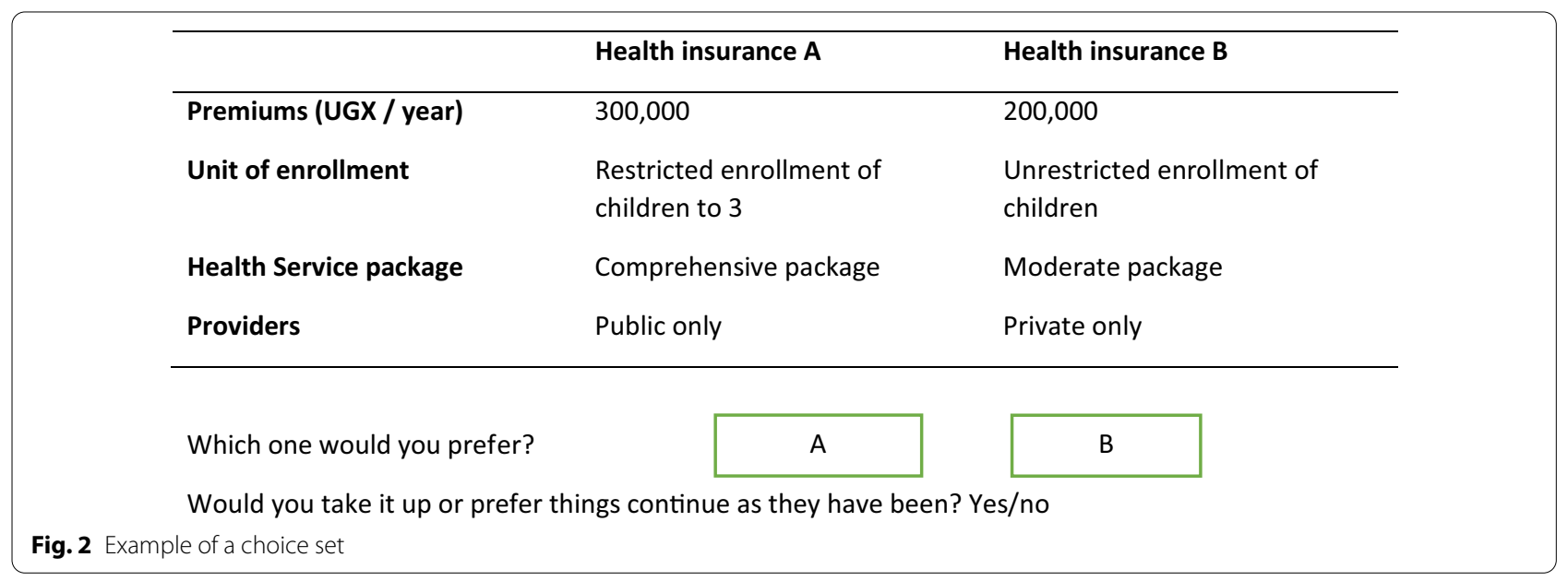

HHs whose heads/spouses refused to participate or were not available at the time of conducting the study.

We used Louviere et al's [40] sample size calculator and determined that a minimum of $54 \mathrm{HHs}$ were required for each area considering each $\mathrm{HH}$ head/ spouse answered 8 choice sets; the choice probability in the population was 0.5 ; the allowed deviation from the true population proportion was 0.1 and; the confidence level was $95 \%$. Considering that each version of the questionnaire is supposed to be answered by at least $30 \mathrm{HHs}$ to avoid imprecise estimations during econometric analysis, the final sample size for each area was revised to $120 \mathrm{HHs}$ such that each of the 4 versions of the questionnaire for each area was answered by at least $30 \mathrm{HHs}$ [26]. The dependent variable was the choice of health insurance plan. The independent variables were the attributes. Table 2 shows all the variables that were measured and their description.

We used face-to-face interviews to collect the data. We purposively selected the Kyebando parish to represent the non-slum communities and the Katanga slum to represent the slum communities. We selected the Kyebando parish 
to represent the non-slum communities because it has several gated residential houses with perimeter walls which are not typical of slum communities [19]. We then applied systematic sampling in the selection of the HHs that participated in the DCE from each area [41, 42]. We selected the reference $\mathrm{HHs}$ for each community randomly and thereafter interviewed every 29th $\mathrm{HH}$ in the slum community and every 20th $\mathrm{HH}$ in the non-slum community. The $\mathrm{HH}$ intervals for each community were obtained by dividing the estimates of the number of $\mathrm{HH}$ in each area by the required sample sizes for each area. In case the approached HH did not meet the inclusion criteria, the next immediate $\mathrm{HH}$ would be approached and the process would be continued until the required sample size was obtained. The questionnaires from each block were distributed randomly to each of the interviewers daily. We edited the data in the field to ensure completeness and consistency.

\section{Data analysis}

We chose the $\mathrm{HH}$ as the unit of analysis because in our study setting, especially among poorer $\mathrm{HHs}$, decisions on seeking health care are usually based on $\mathrm{HHs}$ rather than individuals [30]. We used Chi-square tests and t-tests to assess for differences between the slum and the non-slum communities that may influence their choice behavior. Statistical analysis of the DCE data was based on random utility models. Random utility models are used to analyze the choices of individuals among discrete sets of alternatives.

Equation 1 shows the random utility model. According to the random utility theory, the utility that a $\mathrm{HH}$ (n) obtains from an insurance plan $i$ is given by:

$$
U_{-}(i n)=V\left(x \_i n, B\right)+C \_i n=V\left(x \_i n, B\right)+\mu \_i+\varepsilon_{-} n
$$

where $U \_i n$ is the latent utility for an item $i, \mathrm{~V}\left(X \_i n, B\right)$ is the systematic component which is a function of attributes $x$ and marginal utility $B$. The total error term $\left(C_{-}\right.$in $)$ in mixed logit models is split into two parts. The first part $\mu \_i$ is an individual-specific random effect that takes into account the panel nature of the data. The second part $\varepsilon_{-} n$ is an independent extreme value type- 1 distributed part of the error such that the parameters can be estimated as a logit model [43, 44].

Equation 2 shows the form of the models.

\section{Calculating willingness to pay}

WTP and its confidence interval were calculated using the "wtp" command in STATA 14.2 software using the delta method. WTP was calculated after estimating the model in Eq. 2 with the premium attribute fixed [45].

\section{Validity and predictive power of the models}

Theoretical validity refers to the extent to which the results are consistent with the expectations [46, 47]. Theoretical validity was assessed by checking the direction of association for some of the parameters. For example, the premium attribute was expected to have a negative coefficient (because people do not want to pay more for the same thing). Content validity for a DCE refers to the extent to which the attributes and levels are relevant to the participants $[46,48]$. Content validity was ensured through careful development of the questionnaire that involved a thorough literature review to guide the development of the FGD guide and conducting FGDs with $\mathrm{HH}$ heads/spouses such that the generated attributes and levels are relevant to the communities. We also conducted pilot tests of the questionnaire.

To assess the predictive power of the models, we included one fixed choice set for each area (which was not part of the experimental design) that was answered by all participants. The preference estimates from the choice sets that were part of the experimental design were then used to estimate the probability of choosing one of the alternative health insurance plans in the fixed choice set.

\section{Ethical considerations}

The institutional review board of the School of Public Health, Makerere University approved this study. Informed consent was secured from each person interviewed.

\section{Results}

Characteristics of households

Table 3 summarizes the characteristics of the HHs that

$$
V\left(x_{i n}, B\right)=B_{0}+B_{1} \text { premiums }+B_{2} \text { Both }+B_{3} \text { Private }+B_{4} \text { simple }+B_{5} \text { comprehensive }+B_{6} \text { Restrict }+B_{7} \text { Extended }
$$

where $B$ represents the parameter mean and its standard deviation in the population. All regression labels are defined in Table 1. participated in this study. All participants who agreed to participate in this study completed the questionnaire. Overall, $240 \mathrm{HH}$ heads/spouses were interviewed--120 $\mathrm{HH}$ heads/spouses from the slum community and 120 $\mathrm{HH}$ heads/spouses from the non-slum community. The majority of $\mathrm{HHs}$ were headed by males $(70.4 \%), 65 \%$ 
Table 2 Summary of variables

\begin{tabular}{|c|c|c|}
\hline Variables & Description & Measurement \\
\hline Premiums & $\begin{array}{l}\text { The yearly cost for the health insurance plan in } \\
\text { Ugandan shillings }\end{array}$ & Cost in Ugandan shillings \\
\hline Enrollment ${ }^{\mathrm{a}}$ & $\begin{array}{l}\text { The type of family members allowed by the } \\
\text { health insurance plan }\end{array}$ & $\begin{array}{l}\text { Restricted enrollment of children to } 3=1 \\
\text { Unrestricted enrollment of children }=2 \\
\text { Extended family }=3\end{array}$ \\
\hline Service benefits package ${ }^{b}$ & $\begin{array}{l}\text { The type of benefit packages the health insur- } \\
\text { ance plan offers }\end{array}$ & $\begin{array}{l}\text { Simple benefits package }=1 \\
\text { Moderate benefits package }=2 \\
\text { Comprehensive benefits package }=3\end{array}$ \\
\hline Providers $^{c}$ & The type of providers for the health services & $\begin{array}{l}\text { Public providers }=1 \\
\text { Private providers }=3 \\
\text { Both public and private }=2\end{array}$ \\
\hline Sex & The biological sex of the $\mathrm{HH}$ head & Male $=1$, female $=0$ \\
\hline Age & The age of the $\mathrm{HH}$ head in completed years & Age in completed years \\
\hline Child categories & $\begin{array}{l}\text { The number of children in the } \mathrm{HH} \text { in the follow- } \\
\text { ing categories }\end{array}$ & $\begin{array}{l}\text { Below } 5 \\
\text { Between } 5 \text { and } 10 \\
\text { Between } 10 \text { and } 19 \\
\text { Above } 19\end{array}$ \\
\hline Pay health & $\begin{array}{l}\text { History of paying OOP for health care in public } \\
\text { facilities or paying for health products/ser- } \\
\text { vices in private facilities because they were } \\
\text { not available in public facilities }\end{array}$ & $\begin{array}{l}\mathrm{Yes}=1 \\
\mathrm{No}=0\end{array}$ \\
\hline Marriage status & The marriage status of the $\mathrm{HH}$ head & $\begin{array}{l}\text { Single }=1 \\
\text { Married }=2 \\
\text { Widowed }=3 \\
\text { Divorced }=4 \\
\text { Living together or cohabiting }=6\end{array}$ \\
\hline Occupation & The main occupation of the $\mathrm{HH}$ head & $\begin{array}{l}\text { Farmer }=1 \\
\text { Salaried }=2 \\
\text { Casual worker }=3 \\
\text { Retired }=4 \\
\text { Trade/self-employed }=5 \\
\text { Unemployed }=6 \\
\text { Student }=7 \\
\text { Others }=8\end{array}$ \\
\hline Education level & The highest level of education for the $\mathrm{HH}$ head & $\begin{array}{l}\text { No education }=1 \\
\text { Primary education }=2 \\
\text { Secondary education }=3 \\
\text { Post-secondary education }=4 \\
\text { Vocational education }=5\end{array}$ \\
\hline Possession of health insurance & Any possession of health insurance by the $\mathrm{HH}$ & $\begin{array}{l}\text { Yes }=1 \\
\mathrm{No}=0\end{array}$ \\
\hline Responsible organization & $\begin{array}{l}\text { The arrangement for payment of health insur- } \\
\text { ance by the } \mathrm{HH}\end{array}$ & $\begin{array}{l}\text { Private }=1 \\
\text { Employer based }=0\end{array}$ \\
\hline The usual source of health care & $\begin{array}{l}\text { The usual providers of health care services for } \\
\text { the HH members }\end{array}$ & $\begin{array}{l}\text { Private }=1 \\
\text { Public }=2\end{array}$ \\
\hline Chronic illness in $\mathrm{HH}$ & Any member of the $\mathrm{HH}$ with chronic illness & $\begin{array}{l}\text { Yes }=1 \\
\text { No }=0\end{array}$ \\
\hline Socio-economic status & $\begin{array}{l}\text { The classification of HHs into socio-economic } \\
\text { classes } \\
\text { The assets were modified from the Uganda demo- } \\
\text { graphic and health survey questionnaire [35] }\end{array}$ & $\begin{array}{l}\text { By principle component analysis and wealth index calculation using HH assets. } \\
\text { We considered assets that included ownership of a sofa set, sideboard, wall } \\
\text { watch, house ownership, type of fuel for cooking, floor material, wall mate- } \\
\text { rial, source of drinking, type of toilet facility, sharing of toilet facility, number } \\
\text { of rooms for sleeping, ownership of a bike, ownership of a motorcycle, } \\
\text { ownership of a car, ownership of a bank account, number of transactions }\end{array}$ \\
\hline
\end{tabular}

a Restricted enrollment of children includes parents and only three children. Unrestricted enrollment of children includes parents with no restrictions on the number of children. The extended family includes children, their parents, and grandparents

b Simple service benefits package includes primary health care diseases, minor surgeries, ANC, and family planning; moderate service benefits package includes chronic illnesses for example asthma, hypertension, and diabetes, major surgeries including caesarian sections; comprehensive service benefits package includes cancers, advanced kidney disease, heart surgeries, neurosurgeries, ICU, and special care units

c Public providers include health facilities that are owned by the government; private providers include health facilities that are owned by private individuals and faith-based organization 
had at most three children, $88.7 \%$ reported paying for health services in public health care facilities, 94.0\% were not insured, and $33.6 \%$ had at least one family member with a chronic illness. Also, $67.9 \%$ of $\mathrm{HH}$ heads were either married or living with a partner and $66.7 \%$ had attained at least a senior 4 level of education (equivalent to grade 11 in the United States of America education system) [49].

Compared with the slum community, the non-slum community: had more HHs with more than three children (43.3\% non-slum versus $26.7 \%$ slum, $\mathrm{p}<0.001$ ); had more $\mathrm{HH}$ heads with at least a senior 4 level of education $(40.8 \%$ non-slum versus $26.7 \%$ slum, $\mathrm{p}<0.001)$ and; had more $\mathrm{HH}$ heads who were self-employed $(45.8 \%$ non-slum versus $35.8 \%$ slum, $\mathrm{p}<0.001)$. In terms of socio-economic position, the non-slum community had more HHs in the richest quartile $(40.0 \%$ non-slum versus $10.0 \%$ slum, $\mathrm{p}<0.001$ ), and had $\mathrm{HH}$ heads who were on average earning UGX 248,125 (USD 66.2) (based on currency conversion rates from the OANDA website) [36] per month more than their slum counterparts $(\mathrm{p}<0.001)$. In terms of presence in the $\mathrm{HH}$ of family members with chronic illnesses, the slum community had more HHs with members suffering from chronic illnesses compared with the non-slum community (37.5\% slum versus $30.0 \%$ non-slum, $\mathrm{p}<0.001)$.

\section{Preferences of health insurance attributes}

Tables 4 summarizes $\mathrm{HH}$ preferences for the non-slum and slum communities. Two main effects models were fit to the data: one for the slum community; and the other for the non-slum community. Two models were fit to the data because of differences between the two communities in terms of characteristics that can influence choice behavior that included: $\mathrm{HH}$ characteristics, socioeconomic position, and presence in the $\mathrm{HH}$ of members with chronic illnesses. Additionally, the two sampled communities generated different levels for the premium attribute with the non-slum community suggesting higher premiums.

HHs in the non-slum community had a high preference for health insurance plans that allowed extended family enrollment (parents, their biological children, and grandparents) $(\beta=0.44, \mathrm{P}<0.05)$ as compared to plans that allowed an unrestricted enrollment of children (parents plus any number of their children) and; health insurance plans in which they could receive health care from both private and public health care providers as compared to plans in which they could receive health care from public health care providers only $(\beta=0.81, \mathrm{P}<0.05)$. HHs in the non-slum community had a low preference for health insurance plans that had a simple service benefits package (primary health care diseases, minor surgeries, ANC, and family planning) as compared to plans that had a moderate benefits package (chronic illnesses and major surgeries) $(\beta=-0.97, P<0.05)$ and; health insurance plans that allowed a restricted enrollment of children (parents plus 3 children only) as compared to plans that allowed an unrestricted enrollment of children $(\beta=-$ $0.90, \mathrm{P}<0.05$ ).

HHs in the slum community had a low preference for health insurance plans that allowed a restricted enrollment of children (parents plus 3 children only) $(\beta=-0.32, p<0.05)$ but had a high preference for plans that allowed extended family enrollment (parents, grandparents, and biological children) as compared to plans that allowed an unrestricted enrollment of children (parents plus any number of their children) $(\beta=0.36$, $\mathrm{p}<0.05$ ). HHs in the slum community also had a high preference for health insurance plans in which they could receive health care from both private and public health care providers as compared to plans in which they could receive health care from public health care providers only $(\beta=0.87, \mathrm{p}<0.05)$.

The significant standard deviations for the coefficients of the attributes show that the parameters vary in the population and there is preference heterogeneity among respondents for the health insurance attributes (a possible indication of unmeasured variables influencing preference estimates such as taste differences) $[50,51]$. The premium attribute was modeled as a fixed parameter to more easily calculate WTP [28].

\section{Willingness to pay}

Table 5 summarizes WTP estimates for the slum and the non-slum communities. HHs in the non-slum community were on average willing to pay: UGX 206,960 (USD 55.2) (based on currency conversion rates from the OANDA website) [36] per year for a plan that allowed extended family enrollment rather than one that allowed an unrestricted enrollment of children; UGX 418,932 (USD 111.7) per year for a plan that allowed an unrestricted enrollment of children rather than one that allowed a restricted enrollment of children; UGX 454,727 (USD 121.3) per year for a plan with a moderate service benefits package rather than one with a simple service benefits package and; UGX 377,057 (USD 100.5) per year to receive health care from both private and public health care providers rather than public health care providers only.

HHs in the slum community were on average willing to pay: UGX 36,540 (USD 9.7) per year for a plan that allowed an unrestricted enrollment of children rather than one that allowed a restricted enrollment of children; UGX 40,937 (USD 10.9) per year for a plan that 
Table 3 Characteristics of households that participated in the discrete choice experiment

\begin{tabular}{|c|c|c|c|}
\hline \multirow[t]{2}{*}{ Variable } & Slum community & Non-slum area community & Total \\
\hline & Frequency (percentage) & Frequency (percentage) & Frequency (percentage) \\
\hline \multicolumn{4}{|l|}{ Sex } \\
\hline Female & $34(28.3)$ & $37(30.8)$ & $71(29.6)$ \\
\hline Male & $86(71.7)$ & $83(69.2)$ & $169(70.4)$ \\
\hline Age & Mean 32.49 (SD 8.2) & Mean $37.29(S D=10.6)^{* * *}$ & Mean $=34.89(\mathrm{SD}=9.8)$ \\
\hline \multicolumn{4}{|l|}{ Marriage status } \\
\hline Married & $79(65.8)$ & $84(70.0)$ & $163(67.9)$ \\
\hline Not married & $41(34.2)$ & $36(30.0)$ & $77(32.1)$ \\
\hline \multicolumn{4}{|c|}{ Number of $\mathrm{HH}$ with children } \\
\hline $0-3$ & $88(73.3)$ & $68(56.7)$ & $156(65.0)$ \\
\hline$>3$ & $32(26.7)$ & $52(43.3)^{* * *}$ & $84(35.0)$ \\
\hline \multicolumn{4}{|c|}{ History of paying for health in government facilities } \\
\hline Yes & $107(89.2)$ & $106(88.3)$ & $212(88.3)$ \\
\hline No & $13(10.8)$ & $14(11.7)$ & $28(11.7)$ \\
\hline \multicolumn{4}{|l|}{ Education level } \\
\hline No education & $5(4.2)$ & $5(4.2)$ & $10(4.2)$ \\
\hline Primary education & $44(36.7)$ & $24(20.0)$ & $68(28.3)$ \\
\hline Senior 4 & $32(26.7)$ & $49(40.8)$ & $81(33.8)$ \\
\hline Senior 6 & $21(17.5)$ & $21(17.5)$ & $42(17.5)$ \\
\hline University & $13(10.8)$ & $16(13.3)$ & $29(12.1)$ \\
\hline Vocational institute & $5(4.2)$ & $5(4.2)^{* * *}$ & $10(4.2)$ \\
\hline \multicolumn{4}{|l|}{ Occupation } \\
\hline Salaried employee & $38(31.7)$ & $39(32.5)$ & $77(32.1)$ \\
\hline Casual worker & $17(14.2)$ & $14(11.7)$ & $31(12.9)$ \\
\hline Self-employed & $43(35.8)$ & $55(45.8)$ & $98(40.8)$ \\
\hline Unemployed & $18(15.0)$ & $7(5.8)$ & $25(10.4)$ \\
\hline Others & $84(72.0)$ & $85(70.8)^{* * *}$ & $169(70.4)$ \\
\hline $\mathrm{HH}$ income per month & Mean 367,625 (SD 269,622.7) & Mean 615,750 (SD 645,989)**** & Mean 491,687.5(SD $=510,226.2)$ \\
\hline \multicolumn{4}{|c|}{ HH income per month categories (UGX) } \\
\hline $0-200,000$ & $42(35.0)$ & $14(11.7)$ & $22(9.2)$ \\
\hline $200,001-400,000$ & $44(36.7)$ & $41(34.2)$ & $85(35.4)$ \\
\hline $400,001-600,000$ & $19(15.8)$ & $32(26.7)$ & $51(21.3)$ \\
\hline$>600,001$ & $15(12.5)$ & $33(27.5)^{* * * *}$ & $48(20.0)$ \\
\hline \multicolumn{4}{|c|}{ Possession of health insurance } \\
\hline Yes & $8(6.7)$ & $7(5.9)$ & $16(6.7)$ \\
\hline No & $112(93.3)$ & $113(94.1)$ & $224(93.3)$ \\
\hline \multicolumn{4}{|c|}{ The usual source of health care } \\
\hline Public facilities & $58(48.3)$ & $46(38.3)$ & $104(43.3)$ \\
\hline Private facilities & $62(51.7)$ & $74(61.7)^{* * *}$ & $136(56.7)$ \\
\hline \multicolumn{4}{|l|}{ Chronic illness in $\mathrm{HH}$} \\
\hline Yes & $45(37.5)$ & $36(30.0)$ & $81(33.8)$ \\
\hline No & $75(62.5)$ & $84(70.0)^{* * *}$ & $159(66.2)$ \\
\hline \multicolumn{4}{|l|}{ Socio-economic status } \\
\hline Quantile 1 & $44(37.7)$ & $16(13.3)$ & $60(25.0)$ \\
\hline Quantile 2 & $36(30.0)$ & $24(20.0)$ & $60(25.0)$ \\
\hline Quantile 3 & $28(23.3)$ & $32(26.7)$ & $60(25.0)$ \\
\hline Quantile 4 & $12(10.0)$ & $48(40.0)^{* * * *}$ & $60(25.0)$ \\
\hline
\end{tabular}

$\mathrm{P}$ values for categorical values were based on chi-squared tests while for continuous variables, it was based on t-tests 
Table 4 Household preferences for health insurance attributes

\begin{tabular}{|c|c|c|c|c|}
\hline \multirow[t]{2}{*}{ Attribute } & \multicolumn{2}{|l|}{ Non-slum community } & \multicolumn{2}{|l|}{ Slum community } \\
\hline & Mean (Standard error) & SD (Standard error) & Mean (Standard error) & SD (Standard error) \\
\hline Premium (continuous*10,000 UGX /year) & $-0.21(0.08)^{* *}$ & & $-0.88(0.18)^{* * *}$ & \\
\hline \multicolumn{5}{|l|}{ Enrollment ${ }^{\mathrm{a}}$} \\
\hline Extended family & $0.44(0.20)^{* *}$ & $1.39(0.26)^{* * *}$ & $0.36(0.14)^{* *}$ & $0.09(0.60)$ \\
\hline $\begin{array}{l}\text { Restricted enrollment of children to } 3 \text { (Ref: } \\
\text { unrestricted enrollment of children) }\end{array}$ & $-0.90(0.16)^{* * *}$ & $0.70(0.24)^{*}$ & $-0.32(0.17)^{*}$ & $1.00(0.47)$ \\
\hline \multicolumn{5}{|l|}{ Service benefits package ${ }^{b}$} \\
\hline Simple & $-0.97(0.22)^{* * *}$ & $1.62(0.25)^{* * *}$ & $0.10(0.29)$ & $0.63(0.30)$ \\
\hline Comprehensive (Ref: moderate) & $-0.02(0.14)$ & $0.50(0.29)$ & $-0.14(0.18)$ & $1.30(0.23)^{* * *}$ \\
\hline \multicolumn{5}{|l|}{ Providers ${ }^{c}$} \\
\hline Private only & $-0.08(0.14)$ & $0.46(0.29)$ & $-0.06(0.16)$ & $0.92(0.21)^{* * *}$ \\
\hline Private and public (Ref: Public) & $0.81(0.18)^{* * *}$ & $0.95(0.24)^{* *}$ & $0.87(0.17)^{* * *}$ & $0.96(0.22)^{* * *}$ \\
\hline Constant & $0.02(0.11)$ & & $0.09(0.10)$ & \\
\hline \multicolumn{5}{|l|}{ Model diagnostics } \\
\hline Number of respondents & 120 & & 120 & \\
\hline Number of observations & 1920 & & 1920 & \\
\hline Loglikelihood & -553.00 & & -581.61 & \\
\hline Loglikelihood X^2 & 88.57 & & 70.94 & \\
\hline
\end{tabular}

The non-significant constant suggests that there is no left-right bias in the data. This means that respondents were not likely to choose the left than the right alternative

${ }^{*} \mathrm{p}<0.05,{ }^{* *} \mathrm{p}<0.01,{ }^{* * *} \mathrm{p}<0.001$

${ }^{a}$ Restricted enrollment of children includes parents and only three children; unrestricted enrollment of children includes parents with no restrictions on the number of children and; the extended family includes children, their parents, and grandparents

b Simple service benefits package includes primary health care diseases, minor surgeries, ANC, and family planning; moderate service benefits package includes chronic illnesses (asthma, hypertension, and diabetes) and major surgeries including caesarian sections; comprehensive service benefits package includes cancers, advanced kidney disease, heart surgeries, neurosurgeries, ICU, and special care units

c Public providers include health facilities that are owned by the government; private providers include health facilities that are owned by private individuals and faith-based organizations

allowed extended family enrollment rather one that allowed an unrestricted enrollment of children and; UGX 98,738 (USD 26.3) to receive health care from both private and public health care providers rather than public health care providers only.

\section{Assessing the validity of the results and predictive power of the models}

Most of the estimated coefficients including the coefficient for the premium attribute had the expected signs. The model for the non-slum community predicted that $66.1 \%$ of the $\mathrm{HH}$ heads from the non-slum community would choose health insurance $A$ of the fixed choice question. From the data collected, $64.2 \%$ of the $\mathrm{HHs}$ in the non-slum community chose health insurance A of the fixed choice question. The model for the slum community predicted that $54.5 \%$ of the $\mathrm{HHs}$ from the slum community would choose health insurance A of the fixed choice question. From the data collected, $54.2 \%$ of the HHs from the slum community chose health insurance A of the fixed choice question. These results show that both models had good prediction.

\section{Discussion}

We present data of $\mathrm{HH}$ preferences and WTP for health insurance in the Kawempe division of Kampala city stratified into slum and non-slum communities. To our knowledge, this is the first study from Uganda that has examined preferences for health insurance attributes and their valuation by $\mathrm{HHs}$. We found differences in $\mathrm{HH}$ characteristics between slum and non-slum communities, which may influence their health access choices that ultimately affect their choice of health insurance plans. Although we found differences between the two communities in terms of preferences for the service benefits package, some similarities were identified. For instance, we found that $\mathrm{HHs}$ in both communities preferred health insurance plans that have fewer restrictions on the number of family members allowed and health insurance 
Table 5 Willingness to pay

\begin{tabular}{|c|c|c|}
\hline Attributes & $\begin{array}{l}\text { Non-slum community } \\
\text { WTP }(95 \% \mathrm{Cl})\end{array}$ & $\begin{array}{l}\text { Slum community } \\
\text { WTP }(95 \% \mathrm{Cl})\end{array}$ \\
\hline \multicolumn{3}{|l|}{ Premium } \\
\hline \multicolumn{3}{|l|}{ (continuous*UGX 100,000 per year) } \\
\hline \multicolumn{3}{|l|}{ Enrollment ${ }^{\mathrm{a}}$} \\
\hline \multicolumn{3}{|l|}{ Restricted enrollment of children to 3} \\
\hline Extended family & $-4.19(-7.33,-1.05)$ & $-0.37(-0.76,0.03)$ \\
\hline (Ref: unrestricted enrollment of children) & $2.07(-0.23,4.37)$ & $0.41(0.05,0.77)$ \\
\hline \multicolumn{3}{|l|}{ Service benefits package ${ }^{b}$} \\
\hline \multicolumn{3}{|l|}{ Simple } \\
\hline Comprehensive & $-4.55(-8.26,0.84)$ & $0.12(-0.21,0.45)$ \\
\hline (Ref: moderate) & $-0.09(-1.39,1.22)$ & $-0.15(-0.57,0.26)$ \\
\hline \multicolumn{3}{|l|}{ Providers $^{c}$} \\
\hline \multicolumn{3}{|l|}{ Private and public } \\
\hline Private only & $3.77(0.79,6.75)$ & $0.99(0.49,1.48)$ \\
\hline (Ref: Public) & $0.38(-0.95,1.71)$ & $-0.07(-0.42,0.29)$ \\
\hline \multicolumn{3}{|c|}{$\begin{array}{l}\text { Restricted enrollment of children includes parents and only three children; unrestricted enrollment of children includes parents with no restrictions on the number } \\
\text { of children and; the extended family includes children, their parents, and grandparents }\end{array}$} \\
\hline \multicolumn{3}{|c|}{$\begin{array}{l}\text { b Simple service benefits package includes primary health care diseases, minor surgeries, ANC, and family planning; moderate service benefits package includes } \\
\text { chronic illnesses (asthma, hypertension, and diabetes) and major surgeries including caesarian sections; comprehensive service benefits package includes cancers, } \\
\text { advanced kidney disease, heart surgeries, neurosurgeries, ICU, and special care units }\end{array}$} \\
\hline \multicolumn{3}{|c|}{$\begin{array}{l}\text { c Public providers include health facilities that are owned by the government; private providers include health facilities that are owned by private individuals and } \\
\text { faith-based organizations }\end{array}$} \\
\hline
\end{tabular}

plans in which they can receive health care from both private and public health care providers.

$\mathrm{HHs}$ in both communities preferred health insurance plans that allow extended family enrollment. In Africa, most families are extended families. Therefore, plans that allow extended family enrollment are expected to be preferred as has been indicated in other studies [16, 33, 34]. However, one study that was conducted in Ethiopia had different results with $\mathrm{HHs}$ preferring limited family enrollment [33]. The authors found these results surprising but contend that the respondents may have attached costs to enrolling extended family members, or the cost of health care for their parents may have been shared among siblings. Thus, some of the interviewed participants may not have been directly responsible for the health of their parents [33]. Contrary to our expectations, $\mathrm{HHs}$ in the slum community had a similar preference for health insurance plans that allow a restricted enrollment of children and plans that allow an unrestricted enrollment of children: this may have been because HHs in the slum community had fewer children compared with those in the non-slum community. The greater number of children in the HHs from the non-slum community compared with the slum community was also not expected. A possible explanation for this finding could be due to the $\mathrm{HH}$ heads in the slum community being younger and as their families grow, and possibly their finances improve, they move out of the slum communities. Including more $\mathrm{HH}$ members in the NHIS would be attractive for the majority of HHs in both communities but this needs to be weighed against the other attributes and the possible depletion of resources because of increased demand.

Regarding the service benefits package, $\mathrm{HHs}$ in the non-slum community had a high preference for health insurance plans that had a moderate service benefits package (chronic illnesses and major surgeries) as compared to plans that had either a simple service benefits package (primary health care diseases, minor surgeries, ANC, and family planning) or; a comprehensive service benefits package (cancers, kidney disease, heart surgeries, neurosurgeries, ICU, and special care units). As indicated in other studies, the preference for the service benefits packages depends on the community's perceptions about the costs and the seriousness of the health conditions covered by health insurance $[30,52]$, For instance, in our study, the health conditions under the moderate benefits package are often perceived to be more serious and more costly compared with health conditions under the simple benefits package. For the case of the comprehensive benefits package, the health conditions covered may have been perceived by the $\mathrm{HHs}$ to be rare and therefore not a priority to insure against (possibly because few family members are likely to require management for them). Our results agree with findings from other DCEs in 
which coverage for major surgeries and chronic illnesses was important for the respondents [16, 30]. In contrast, $\mathrm{HH}$ from the slum community equally preferred all forms of the service benefits packages. This may be explained by the fact that slum communities are disproportionately affected by most diseases compared with the rest of the communities and therefore, it was hard for them to decide on the best benefits package. Therefore, the $\mathrm{MoH}$ may need to modify the scheme for poor communities.

Furthermore, HHs in both communities preferred plans in which they can receive health care from both private and public health care providers. These findings agree with several other studies that found that, given the opportunity, individuals prefer to receive health care from both private and public healthcare providers [33, 38]. The preference for both providers in our study is complex because of the various health system issues. For instance, on one hand, the public is aware of the public health facilities' challenges such as health worker absenteeism, low staffing, frequent breakdown of equipment due to poor maintenance, and unavailability of drugs. On the other hand, the public health care facilities, particularly the referral hospitals, are known to have better infrastructure and more qualified staff $[53,54]$. The preference for both providers may also be explained by the HH's concerns about the profit-making motives of private health care providers that may compromise their services $[35,54]$. Therefore, the MoH may need to contract with some private providers in addition to public providers in NHIS to make the scheme more attractive and acceptable for the majority of HHs.

Our study shows that HHs in the non-slum community are willing to pay more for the preferred attributes compared with their counterparts in the slum community. This is not surprising and can be explained by a higher income and awareness level of the benefits of health insurance in the non-slum community compared with the slum community [30,52]. For instance, in our study, the non-slum community had more $\mathrm{HH}$ heads who had attained at least a Senior 4 level of education (equivalent to grade 11 in the United States of America education system) [49] compared with the slum community. The higher education attainment by $\mathrm{HH}$ heads in the non-slum community may have helped them to earn more income and have a higher level of awareness for the benefits of health insurance [30]. As indicated in other studies, the higher the level of education, the greater the WTP for health insurance $[13,52]$.

This study also assessed the validity of the estimated models and found that most of the coefficients including the premium attribute had the expected signs. The premium attribute had a negative sign in both models which shows that as the premiums increased, the preferences for health insurance plans decreased [16]. This adds to the theoretical validity of the results.

\section{Strengths and limitations of this study}

The strength of this study--based on the design--is that DCEs not only estimate $\mathrm{HH}$ preferences for the attributes of health insurance, but can also be used to estimate valuation of the attributes, and thus, are not as limited as contingent methods that can estimate WTP for health insurance but not attributes' preferences.

The limitation of this study--based on the study design--is that the respondents may face challenges in answering the multiple questions that require tradeoffs characteristic of DCEs.

In terms of generalizability, our findings may apply to Kampala city because the residents of Kampala are mainly divided into the slum and non-slum dwellers. However, these results may also apply to other urban populations of Uganda with similar contexts as Kampala. The results from the slum community may also reflect rural preferences and willingness to pay since most of the slum dwellers are usually immigrants from rural communities $[55,56]$.

\section{Conclusions and recommendations}

Our study reveals that $\mathrm{HHs}$ in the slum and the non-slum communities prefer and value plans that include both private and public health care providers. Therefore, for the type of health care providers to be included in the NHIS, we recommend that the $\mathrm{MoH}$ considers contracting with some private health care providers to make the scheme more attractive and acceptable for the majority of HHs. Although findings from our study suggest that more $\mathrm{HHs}$ may join the NHIS if more family members are allowed, this needs to be weighed against possible depletion of resources. For the service benefits package to include in the NHIS, we advise the $\mathrm{MoH}$ to prioritize providing coverage for chronic illnesses and major surgeries especially for the non-slum communities rather than prioritizing specialized care units. We recommend that the $\mathrm{MoH}$ subsidizes the scheme for the poor communities (slum and rural) to make the scheme affordable for the poor while at the same time set reasonable premiums for the non-slum communities to raise adequate funds for the health sector.

Further research may be needed targeting specifically people who work in the formal sector and the richest class to provide information about these groups' preferences and WTP. Qualitative research targeting policymakers in the $\mathrm{MoH}$, the health workers, the district health teams and, the legislators may also be needed 
to get their perspectives on how the health insurance scheme should be designed.

\begin{abstract}
Abbreviations
Cl: Confidence interval; DCE: Discrete choice experiment; FGD: Focused group discussion; GDP: Gross domestic product; $\mathrm{HH}$ : Household; ICU: Intensive care unit; IPD: Inpatient department; MoH: Ministry of Health; MoPS: Ministry of Public service; NHIS: National health insurance scheme; OECD: Organization for Economic Cooperation and Development; OOP: Out of pocket; OPD: Outpatient department; SD: Standard deviation; UBOS: Uganda Bureau of Statistics; UGX: Uganda shillings; UHC: Universal health coverage; USD: United States dollars; WB: World Bank; WHO: World Health Organization; WTP: Willingness to pay.
\end{abstract}

\section{Supplementary Information}

The online version contains supplementary material available at https://doi. org/10.1186/s12962-021-00274-8.

Additional file 1. FGD guide.

\section{Acknowledgements}

None.

\section{Authors' contributions}

EK: conceptualization; methodology; validation; formal analysis; investigation; writing the original draft; visualization; and project administration. RMK: conceptualization; writing the original draft; validation; preparation of the manuscript; and Supervision of the work. EEK: conceptualization; validation; writing the original draft; preparation of the manuscript; and supervision. All authors read and approved the final manuscript.

\section{Funding}

None.

\section{Availability of data and materials}

Data is available from the corresponding author at reasonable request.

\section{Declarations}

\section{Ethical approval}

The authors obtained ethical approval from the Institutional Review Board of the School of Public Health, Makerere University.

\section{Consent to participate}

Informed consent was obtained from all individual participants included in the study.

\section{Consent for publication}

Not applicable.

\section{Competing interests}

The authors declare that they have no competing interests.

\section{Author details}

${ }^{1}$ Department of Health Policy and Planning, School of Public Health, College of Health Sciences, Makerere University, Kampala, Uganda. ${ }^{2}$ Department of international Development, The London School of Economics and Political Science, London, UK.

Received: 10 November 2020 Accepted: 7 April 2021

Published online: 20 April 2021

\section{References}

1. Rosa W, editor. Transforming Our World: The 2030 Agenda for Sustainable Development. In: A New Era in Global Health [Internet]. New York, NY: Springer Publishing Company; 2017. https://doi.org/10.1891/9780826190 123.ap02

2. WHO. Health systems financing: the path to universal coverage, WORLD HEALTH REPORT 2010. Geneva, Switzerland: World Health Organization; 2010. http://www.who.int/whr/2010/en/

3. WHO. Global Health Expenditure Database [Internet]. 2020. https:// data.worldbank.org/indicator/SH.XPD.CHEX.GD.ZS?locations=ZG-1W. Accessed 16 Jun 2020

4. Ottersen T, Elovainio R, Evans DB, McCoy D, Mcintyre D, Meheus F, et al. Towards a coherent global framework for health financing: recommendations and recent developments. Health Econ Policy Law. 2017;12(2):285-96.

5. MoH. National Health Accounts 2014/15 -2015/16 [Internet]. Kampala: Ministry of Health; 2018. http://library.health.go.ug/publications/healthinsurance/national-health-accounts-fy-201415-201516. Accessed 17 May 2019

6. WHO. The World health report: 2000: Health systems: improving performance. Geneva: World Health Organization; 2000. https://apps.who.int/ iris/handle/10665/42281

7. Woldemichael A, Gurara D, Shimeles A. The impact of community-based health insurance schemes on out-of-pocket healthcare spending: evidence from Rwanda. IMF Work Pap. 2019;1(19):1.

8. Okoroh J, Essoun S, Seddoh A, Harris H, Weissman JS, Dsane-Selby L, et al. Evaluating the impact of the national health insurance scheme of Ghana on out-of-pocket expenditures: a systematic review. BMC Health Serv Res. 2018;18(1):426.

9. MoH. Proposed national health insurance scheme, 2019. Ministry of Health; 2019. http://www.health.go.ug/download/file/fid/2320

10. Haven N, Dobson AE, Yusuf K, Kellermann S, Mutahunga B, Stewart AG, et al. Community-based health insurance increased health care utilization and reduced mortality in children under-5, around Bwindi Community Hospital Uganda between 2015 and 2017. Front Public Health. 2018;6:281.

11. Mutebi A, Muhumuza Kananura R, Ekirapa-Kiracho E, Bua J, Namusoke Kiwanuka S, Nammazi G, et al. Characteristics of community savings groups in rural Eastern Uganda: opportunities for improving access to maternal health services. Glob Health Action. 2017;10(sup4):1347363.

12. Carson R. Contingent valuation: a user's guide. San Diego: University of California, Department of Economics. Discussion Paper; 1999. p. 34.

13. Basaza R, Kyasiimire EP, Namyalo PK, Kawooya A, Nnamulondo P, Alier KP. Willingness to pay for Community Health Insurance among taxi drivers in Kampala City, Uganda: a contingent evaluation. Risk Manag Healthc Policy. 2019;12:133-43.

14. Birungi V. Willingness to Pay for Community Health Insurance Among Households in Wakiso District, Uganda. [Internet] [Thesis]. International Health Sciences University.; 2014. http://dspace.ciu.ac.ug/xmlui/handle/ 123456789/542. Accessed 4 Aug 2019.

15. Ruhweza M. Willingness to pay for community health insurance among households in Jinja district. 2007; http://makir.mak.ac.ug/handle/10570/ 338. Accessed 4 Aug 2019

16. Abiiro GA, Torbica A, Kwalamasa K, De Allegri M. Eliciting community preferences for complementary micro health insurance: a discrete choice experiment in rural Malawi. Soc Sci Med. 2014;1982(120):160-8.

17. Basaza R, Criel B, Van der Stuyft P. Low enrolment in Ugandan Community Health Insurance Schemes: underlying causes and policy implications. BMC Health Serv Res. 2007;7(1):105.

18. Brau R, Lippi BM. Eliciting the demand for long-term care coverage: a discrete choice modelling analysis. Health Econ. 2008;17(3):411-33.

19. Kampala City Council Authority. Kawempe-Grades [Internet]. Kampala City Council Authority; https://www.kcca.go.ug/uDocs/KawempeGrades.pdf

20. UBOS. National Population and Housing Census 2014: Area Specific Profile series [Internet]. Kampala, Uganda; 2017 Apr. https://www.ubos. org/onlinefiles/uploads/ubos/2014CensusProfiles/KAMPALA-KCCA.pdf

21. MoH. National Health Facility Master List 2018 [Internet]. Ministry of Health; 2018. http://library.health.go.ug/publications/health-infrastruc ture-physical-infrastructure/health-facility-inventory 
22. Kampala City Council Authority. Statistical Abstract for Kampala City [Internet]. Kampala City Council Authority; 2019. https://www.kcca.go. ug/media/docs/Statistical-Abstract-2019.pdf

23. UN-HABITAT. Situation Analysis of Informal Settlements in Kampala. Nairobi, Kenya: UN-HABITAT; 2007.

24. Coast J, Al-Janabi H, Sutton EJ, Horrocks SA, Vosper AJ, Swancutt DR, et al. Using qualitative methods for attribute development for discrete choice experiments: issues and recommendations. Health Econ. 2012;21(6):730-41.

25. Mangham LJ, Hanson K, McPake B. How to do (or not to do) ... Designing a discrete choice experiment for application in a low-income country. Health Policy Plan. 2009;24(2):151-8.

26. Ryan M, Gerard K, Amaya-Amaya M, editors. Using Discrete Choice Experiments to Value Health and Health Care [Internet]. Springer Netherlands; 2008. (The Economics of Non-Market Goods and Resources). https:// www.springer.com/gp/book/9781402040825. Accessed 4 Aug 2019

27. Ryan M, Gerard K. Using discrete choice experiments to value health care programmes: current practice and future research reflections. Appl Health Econ Health Policy. 2003;1(2):55-64.

28. WHO. How to Conduct a Discrete Choice Experiment for Health Workforce Recruitment and Retention in Remote and Rural Areas: A User Guide with Case Studies [Internet]. Geneva, Switzerland; 2012. https:// www.who.int/hrh/resources/dceguide/en/. Accessed 6 Aug 2019.

29. Abiiro GA, Leppert G, Mbera GB, Robyn PJ, De Allegri M. Developing attributes and attribute levels for a discrete choice experiment on micro health insurance in rural Malawi. BMC Health Serv Res. 2014;14(1):235.

30. Kamara J, Bonet MJ, Mesnard A. A discrete choice experiment to elicit the willingness to pay for health insurance by the informal sector workers in Sierra Leone. Int J Health Econ Policy. 2018;3(1):1.

31. Kazemi Karyani A, Akbari Sari A, Woldemichael A. Eliciting preferences for health insurance in Iran using discrete choice experiment analysis. Int J Health Policy Manag. 2019;8(8):488-97

32. Kazemi Karyani A, Rashidian A, Akbari Sari A, Emamgholipour SS. Developing attributes and levels for a discrete choice experiment on basic health insurance in Iran. Med J Islam Repub Iran. 2018;28(32):26.

33. Obse A, Ryan M, Heidenreich S, Normand C, Hailemariam D. Eliciting preferences for social health insurance in Ethiopia: a discrete choice experiment. Health Policy Plan. 2016;31(10):1423-32.

34. Trujillo AJ, Ruiz F, Bridges JFP, Amaya JL, Buttorff C, Quiroga AM. Understanding consumer preferences in the context of managed competition. Appl Health Econ Health Policy. 2012;10(2):99-111.

35. Obse A, Hailemariam D, Normand C. Knowledge of and preferences for health insurance among formal sector employees in Addis Ababa: a qualitative study. BMC Health Serv Res. 2015;15:1-1.

36. OANDA Currency Converter [Internet]. OANDA. 2020; https://www1. oanda.com/currency/converter/. Accessed 6 Apr 2020.

37. UBOS. Uganda National Household Survey 2016/2017 [Internet]. Kampala, Uganda; 2018. https://www.ubos.org/wp-content/uploads/publi cations/03_20182016_UNHS_FINAL_REPORT.pdf.

38. Anoo Nanna. Health Insurance in Developing Countries: Willingness to Pay for Health Insurance in Thailand using Discrete Choice Experiment Methods [Internet]. Curtin University; 2011. https://espace.curtin.edu.au/ handle/20.500.11937/945
39. Louviere JJ, Islam T, Wasi N, Street D, Burgess L. Designing discrete choice experiments: do optimal designs come at a price? J Consum Res. 2008;35(2):360-75.

40. Louviere J, Hensher D, Swait J. Stated choice methods: analysis and application, vol. 17. Cambridge: Cambridge University Press; 2000.

41. Sayed A, Ibrahim A. Recent developments in systematic sampling: a review. J Stat Theory Pract. 2018;12(2):290-310.

42. Kalton G. Systematic Sampling. In: Wiley StatsRef: Statistics Reference Online [Internet]. American Cancer Society; 2017. p. 1-6. https://doi.org/ 10.1002/9781118445112.stat03380.pub2. Accessed 2 Feb 2021

43. McFadden D. The measurement of urban travel demand. J Public Econ. 1974;3(4):303-28.

44. Manski CF. The structure of random utility models. Theory Decis. 1977;8(3):229.

45. StataCorp. Stata Statistical Software. College Station, TX: StataCorp LP. 2015.

46. Janssen EM, Marshall DA, Hauber AB, Bridges JFP. Improving the quality of discrete-choice experiments in health: how can we assess validity and reliability? Expert Rev Pharmacoecon Outcomes Res. 2017;17(6):531-42.

47. Ryan M, Scott DA, Reeves C, Bate A, van Teijlingen ER, Russell EM, et al. Eliciting public preferences for healthcare: a systematic review of techniques. Health Technol Assess Winch Engl. 2001;5(5):1-186.

48. Mühlbacher A, Johnson FR. Choice Experiments to Quantify Preferences for Health and Healthcare: State of the Practice. Appl Health Econ Health Policy. 2016;14(3):253-66.

49. WB. World Data on Education: Seventh edition 2010-11 [Internet]. World Bank Publications; 2012. http://www.ibe.unesco.org/fileadmin/user_ upload/Publications/WDE/2010/pdf-versions/Uganda.pdf

50. Kjaer T, Gyrd-Hansen D. Preference heterogeneity and choice of cardiac rehabilitation program: results from a discrete choice experiment. Health Policy Amst Neth. 2008;85(1):124-32.

51. Train KE. Recreation demand models with taste differences over people. Land Econ. 1998;74(2):230-9.

52. Dakoye D, Anguyo R, Anguyo DDM Onzima R, Govule P, Katongole S, Ayiko R, et al. Communities'Willingness to Pay for Healthcare in Public Health Facilities of Nakasongola District, Uganda. 2015; 3:248-53

53. Burnham GM, Pariyo G, Galiwango E, Wabwire-Mangen F. Discontinuation of cost-sharing in Uganda. Bull World Health Organ. 2004;82(3):187-95.

54. Kwesiga B, Zikusooka CM, Ataguba JE. Assessing catastrophic and impoverishing effects of health care payments in Uganda. BMC Health Serv Res. 2015;15(1):30

55. Marx B, Stoker T, Suri T. The economics of slums in the developing world. J Econ Perspect. 2013;27(4):187-210.

56. Leeuwen JMV, Sekeramayi T, Martell C, Feinberg M, Bowersox-Daly S. A Baseline Analysis of the Katanga Slums: Informing Urban Public Policy in Kampala, Uganda. Afr Popul Stud. 201731 (2). https://aps.journals.ac.za/ pub/article/view/1057. Accessed 2 Feb 2021.

\section{Publisher's Note}

Springer Nature remains neutral with regard to jurisdictional claims in published maps and institutional affiliations.
Ready to submit your research? Choose BMC and benefit from:

- fast, convenient online submission

- thorough peer review by experienced researchers in your field

- rapid publication on acceptance

- support for research data, including large and complex data types

- gold Open Access which fosters wider collaboration and increased citations

- maximum visibility for your research: over 100M website views per year

At BMC, research is always in progress.

Learn more biomedcentral.com/submissions 